\title{
Nutritional consequences of endoluminal gastroplasty in the treatment of morbidly obese patients
}

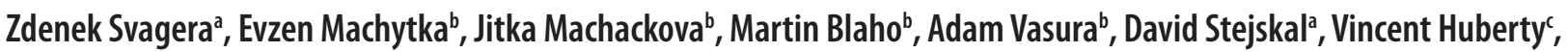 \\ Marek Buzga ${ }^{\mathrm{a}, \mathrm{d}}$
}

Background. The Endoscopic sleeve gastroplasty (ESG) is one of the new advanced restrictive techniques of bariatric endoscopy. The principle of this bariatric technique is the reduction of stomach volume through endoscopic plication. The long-term efficacy and metabolic effects of this procedure are the subject of this study.

Methods. 20 patients were enrolled; four men, sixteen women. Then they were followed for 24 months in terms of glycemic control, body composition, vitamin, and nutritional status. Observed parameters included glucose, triacylglycerols, high- and low-density lipoprotein cholesterol, micro and macro nutrients, fat mass, and lean body mass.

Results. We observed significant weight loss and a decrease body composition resulted from procedure vs. baseline, with levels of blood glucose also showing statistically significant reductions. The most notable decline in measured values was observed in period six months after the procedure. No significant changes were observed in measurement of micronutrients.

Conclusions. Good restriction results were obtained following ESG, which might be mediated via altered glucose metabolism. The ESG method has shown a positive effect on fat and muscle mass. Unlike surgical methods, there were no deficits or deficiencies, especially in terms of essential vitamin levels.

Key words: bariatric endoscopy, body weight loss, obesity, nutrition, vitamins

Received: February 24, 2021; Revised: April 1, 2021; Accepted: May 12, 2021; Available online: May 27, 2021

https://doi.org/10.5507/bp.2021.032

(c) 2021 The Authors; https://creativecommons.org/licenses/by/4.0/

anstitute of Laboratory Medicine, University Hospital Ostrava, Ostrava, Czech Republic

${ }^{b}$ Department of Gastroenterology, University Hospital Ostrava, Ostrava, Czech Republic

'Department of Gastroenterology, Erasme Hospital, Universite Libre de Bruxelle, Belgium

${ }^{d}$ Department of Physiology and Pathophysiology, Research Obesity Centre, Faculty of Medicine, University of Ostrava, Czech Republic Corresponding author: Marek Buzga, e-mail: marek.buzga@osu.cz

\section{INTRODUCTION}

Obesity is currently one of the biggest health problems in the world, including the whole complex of comorbidities. Many studies have described the pathophysiological relationships between overweight and cardiovascular disease as well as type 2 diabetes and metabolic syndrome ${ }^{1,2}$. Current treatment options for obesity include lifestyle therapy, pharmacotherapy, and bariatric surgery ${ }^{3}$. Surgery is currently one of the most successful procedures with which to resolve morbid obesity. Nevertheless, this type of treatment has had a limited impact on treating epidemic of obesity as overweight, class I and II obese individuals without medical comorbidities are not indicated for bariatric surgery. Some patients with various degrees of obesity do not have access to surgical treatment or are unable to accept a surgical solution due to fear of the procedure and subsequent complications $\mathrm{s}^{4,5}$.

Although bariatric surgery is very effective, adverse effects that are not uncommon have been documented. The development of surgical techniques is also a great effort to reduce their incidence. Many studies have focused on postoperative surgical complications, digestive tract $^{6,7}$, and about nutritional complications of bariatric surgery ${ }^{8}$. With regard to the extent of intervention in the digestive tract, nutritional complications have been very well described, especially in malabsorption procedures ${ }^{9}$, nevertheless, deficiencies were recently described after restrictive surgery ${ }^{10,11}$. The most frequent deficiencies reported concern iron, calcium, and vitamins B1, B12, and B9 $\left(\right.$ ref. $\left.^{12-14}\right)$.

Complications and some limitations of current bariatric surgery have led in recent years to the development of new endoscopic techniques that would be less aggressive, but would be less risk for patients in terms of subsequent adverse events. Endoscopic treatment of obesity has proven to be a method that is more effective than pharmacological treatment and at the same time safe, with lower financial costs and better available to patients than bariatric surgery ${ }^{15}$. Most of the endoscopic studies focused on the impact on weight loss, feasibility, and safeness of these procedures ${ }^{16,17}$ and on the impact on diabetes ${ }^{18}$, it is quite interesting that there are few works that deal with the nutritional complications of endoscopic bariatric surgery.

The aim of the study was to evaluate changes in nutritional status and selected biochemical parameters of blood of patients after endoscopic treatment of obesity 
in the early postoperative period - the 24 months after surgery.

\section{MATERIALS AND METHODS}

The study was approved by the Ethics Committee at the Faculty of Medicine, University of Ostrava, in accordance with the ethical standards of the Helsinki Declaration of 1975, as amended in 2000. The study had a prospective, observational, and open-label design (ClinicalTrials.gov registration: NCT02582229). A prospective interventional study in patients following Endoscopic sleeve gastroplasty (ESG) was carried out between January 2016 and April 2016.

Inclusion criteria included a BMI $35-40 \mathrm{~kg} / \mathrm{m}^{2}$ and an age of 21-64 years, as per IFSO criteria. Exclusion criteria included a BMI $>40 \mathrm{~kg} / \mathrm{m}^{2}$, GI stenosis or obstruction, previous bariatric surgery, balloon or other endoscopic obesity-related therapy, gastro-duodenal ulcer, absorption disorders, and diabetes mellitus.

\section{Endomina procedure}

The Endoscopic sleeve gastroplasty (ESG) method was performed using the Endomina triangulation platform device (Endo Tools Therapeutics SA - ETT, Gosselies, Belgium) performed with the patients under general anesthesia according to the method described by Huberty et al. ${ }^{5}$

\section{Body composition measurements}

A body composition was assessed in all probands using the dual-emission X-ray absorptiometry (DXA) method (Discovery A; Hologic, Waltham, MA, USA). The following parameters were monitored: fat mass $(\mathrm{kg})$, fat (\%), and lean body mass (LBM; $\mathrm{kg}$ ). The densitometer was calibrated according to the manufacturer's recommendations and the precision error was established ${ }^{19}$. Height was measured in centimeters and weight in kilograms using a standard scale. The weight was measured by a weighing machine with a calibration up to a weight of $250 \mathrm{~kg}$.

\section{Blood tests}

Blood draws were performed the morning after an overnight fast, before the planned procedure, and then again at visit $6,12,18$, and 24 months. Blood samples were processed for analysis within 20 minutes of collection. Serum concentrations of glucose, triacylglycerols, total cholesterol, high- and low-density lipoprotein cholesterol, prealbumin, albumin, total protein, sodium, potassium, chloride, magnesium, calcium, iron and phosphorous were assessed (AU 5820, Beckman Coulter, Inc., Brea, CA, USA). Analysis of all parameters showed inter-assay variation coefficients lower than $5 \%$.

Thyroid stimulating hormone, insulin, folic acid, and vitamin B12 were determined by Access DxI (Beckman Coulter, Inc., Brea, CA, USA) with inter-assay CV 4.1, $4.8,6.1,6.4 \%$. Intact parathyrin and ferritin were deter- mined by Centaur (Siemens Healthcare Diagnostics Inc., Tarrytown, NY, USA) with CV 4.7, 4.6\%. HbA1c was assessed by Tosoh G8 (Tosoh Corporation, Tokyo, Japan) with inter-assay $\mathrm{CV} 1.6 \%$. To reduce analytical variation, vitamins derived from fat tissue from all patients were analyzed in the same run (i.e. simultaneously). Blood samples were stored at $-80^{\circ} \mathrm{C}$ until analysis. Vitamin A, vitamin E, vitamin C, 25(OH)D in plasma were performed on Agilent 1100 HPLC system with UV/VIS detection (Agilent Technologies, Inc., CA, USA) using RECIPE kits (RECIPE, München, Germany) with inter-assay CV lower than 5\%. Vitamin B1, B2 in whole blood and vitamin B6 in plasma were measured by Hitachi Lachrom HPLC system with FLD (Hitachi High-Technologies Corporation, Tokyo, Japan) using RECIPE kits (RECIPE, München, Germany) with inter-assay CV lower than 5\%.

\section{Statistical analysis}

Data analysis was with basic descriptive statistics (median, mean, standard deviation, and frequency tables). On the basis of the Shapiro-Wilk normality test, we compared the parameters by means of the two-sample t-test, the two-sample Wilcoxon rank-sum (Mann-Whitney) test. The paired t-test and Wilcoxon rank-sum test were used to assess parameter changes over time vs. baseline. Statistical tests were evaluated at the $5 \%$ level of significance with data processed using the SPSS, version 24 (IBM SPSS, Chicago, IL).

\section{RESULTS}

\section{Subject demographics}

A total of 20 subjects were enrolled between January 2016 and March 2016 and underwent successful following Endoscopic sleeve gastroplasty (ESG). The study population was $20 \%$ male ( 4 men) and $75 \%$ female (16) women, which had a mean age of $39.1 \pm 8.1$ years and a mean baseline BMI of $37.2 \pm 2.6 \mathrm{~kg} / \mathrm{m}^{2}$. All subjects have completed one-year follow-up clinic visits.

\section{Preoperative micro and macro nutritional parameters}

In the week before the operation, venous blood was

Table 1. Absolute values and rates of deficiency in micronutrients in preoperative endoscopic gastric plication $(n=20)$.

\begin{tabular}{lcc}
\hline Micronutrients [units] & Absolute values & Deficiency $[\mathrm{n}(\%)]$ \\
\hline Vitamin A [ $\mu \mathrm{mol} / \mathrm{L}]$ & $2.3 \pm 0.4$ & 0 \\
Vitamin E $[\mu \mathrm{mol} / \mathrm{L}]$ & $31.4 \pm 6.6$ & 0 \\
$25(\mathrm{OH}) \mathrm{D}[\mathrm{nmol} / \mathrm{L}]$ & $38.2 \pm 14.7$ & $16(80)$ \\
Vitamin D3 [nmol/L] & $53.4 \pm 19.6$ & $2(10)$ \\
Vitamin B1 [nmol/L] & $154.4 \pm 18.2$ & 0 \\
Vitamin B6 [nmol/L] & $47.7 \pm 29.5$ & $2(10)$ \\
Vitamin B12 [ng/L] & $340.5 \pm 131.5$ & 0 \\
Folate $[\mu \mathrm{g} / \mathrm{L}]$ & $7.46 \pm 2.8$ & 0 \\
Vitamin C $[\mu \mathrm{mol} / \mathrm{L}]$ & $47.3 \pm 18.6$ & $1(5)$ \\
Iron $[\mu \mathrm{mol} / \mathrm{L}]$ & $17.1 \pm 9.5$ & $8(40)$ \\
\hline
\end{tabular}


Table 2. Anthropometric parameters before and 6, 12, 18, and 24 months after ESG ( $n=20)$.

\begin{tabular}{lccccccccc}
\hline & \multirow{2}{*}{ Baseline } & \multicolumn{7}{c}{ Postoperative } \\
\cline { 3 - 10 } ID & & 6 months & $P$ & 12 months & $P$ & 18 months & $P$ & 24 months & $P$ \\
\hline Weight $[\mathrm{kg}]$ & $104.9 \pm 11.9$ & $97.3 \pm 11.4$ & 0.000 & $98.9 \pm 11.9$ & 0.007 & $100.8 \pm 12.5$ & 0.011 & $101.1 \pm 10.6$ & 0.035 \\
BMI [kg/m²] & $37.2 \pm 2.6$ & $34.5 \pm 3.1$ & 0.000 & $34.8 \pm 3.4$ & 0.008 & $35.5 \pm 2.9$ & 0.044 & $36.1 \pm 3.7$ & 0.147 \\
LBM [kg] & $60.5 \pm 9.8$ & $58.5 \pm 10.1$ & 0.004 & $59.1 \pm 9.9$ & 0.083 & $61.1 \pm 11.1$ & 0.463 & $61.9 \pm 13.1$ & 0.746 \\
FAT [kg] & $44.4 \pm 5.9$ & $38.9 \pm 7.2$ & 0.000 & $40.8 \pm 5.4$ & 0.006 & $40.4 \pm 7.4$ & 0.035 & $41.2 \pm 8.9$ & 0.114 \\
FAT [\%] & $42.5 \pm 4.6$ & $40.1 \pm 5.9$ & 0.001 & $39.9 \pm 6.3$ & 0.034 & $39.9 \pm 6.9$ & 0.271 & $40.1 \pm 7.3$ & 0.127 \\
\hline
\end{tabular}

Results are expressed as the mean \pm standard deviation, and significance is expressed as the difference between the selected month and baseline measurement. $B M I$ body mass index, $L B M$ lean body mass

Table 3. Nutritional parameters before and 6, 12, 18, and 24 months after ESG ( $n=20)$.

\begin{tabular}{|c|c|c|c|c|c|c|c|c|c|}
\hline & \multirow{2}{*}{ Baseline } & \multicolumn{8}{|c|}{ Postoperative } \\
\hline & & 6 month & $P$ & 12 month & $P$ & 18 month & $P$ & 24 month & $P$ \\
\hline Glucose [mmol/L] & $5.8 \pm 0.8$ & $5.4 \pm 0.7$ & 0.009 & $5.6 \pm 0.7$ & 0.016 & $5.7 \pm 0.8$ & 0.074 & $5.7 \pm 0.9$ & 0.099 \\
\hline $\mathrm{HbA} 1 \mathrm{c}[\mathrm{mmol} / \mathrm{mol}]$ & $37 \pm 5.1$ & $36 \pm 4.2$ & 0.088 & $37 \pm 4.1$ & 0.114 & $38 \pm 3.7$ & 0.641 & $37 \pm 4.3$ & 0.101 \\
\hline Insulin $[\mathrm{mU} / \mathrm{L}]$ & $105.3 \pm 39.6$ & $78.9 \pm 37.1$ & 0.026 & $88.9 \pm 29.2$ & 0.048 & $145.9 \pm 87.5$ & 0.170 & $132.9 \pm 92.1$ & 0.400 \\
\hline $\mathrm{TG}[\mathrm{mmol} / \mathrm{L}]$ & $1.6 \pm 0.6$ & $1.4 \pm 0.6$ & 0.046 & $1.5 \pm 0.6$ & 0.286 & $1.5 \pm 0.7$ & 0.449 & $1.4 \pm 0.6$ & 0.229 \\
\hline Cholesterol [mmol/L] & $5.3 \pm 0.9$ & $5.4 \pm 1.1$ & 0.482 & $5.4 \pm 1.0$ & 0.867 & $5.6 \pm 1.1$ & 0.931 & $5.4 \pm 0.9$ & 0.338 \\
\hline $\mathrm{LDL}[\mathrm{mmol} / \mathrm{L}]$ & $3.6 \pm 0.8$ & $3.7 \pm 0.9$ & 0.600 & $3.6 \pm 0.9$ & 0.935 & $3.7 \pm 0.9$ & 0.452 & $3.6 \pm 0.8$ & 0.036 \\
\hline $\mathrm{HDL}[\mathrm{mmol} / \mathrm{L}]$ & $1.3 \pm 0.2$ & $1.4 \pm 0.3$ & 0.336 & $1.4 \pm 0.3$ & 0.044 & $1.3 \pm 0.3$ & 0.471 & $1.3 \pm 0.2$ & 0.476 \\
\hline Albumin $[\mathrm{g} / \mathrm{L}]$ & $42.9 \pm 3.1$ & $42.9 \pm 2.2$ & 0.906 & $43.1 \pm 2.6$ & 0.076 & $43.6 \pm 2.7$ & 0.380 & $43.0 \pm 2.9$ & 0.745 \\
\hline Prealbumin $[\mathrm{g} / \mathrm{L}]$ & $0.3 \pm 0.1$ & $0.3 \pm 0.1$ & 0.840 & $0.3 \pm 0.0$ & 0.290 & $0.3 \pm 0.1$ & 0.174 & $0.3 \pm 0.1$ & 0.412 \\
\hline Total protein $[\mathrm{g} / \mathrm{L}]$ & $70.6 \pm 3.3$ & $70.9 \pm 3.5$ & 0.759 & $70.3 \pm 3.3$ & 0.227 & $71.6 \pm 4.8$ & 0.356 & $70.6 \pm 4.2$ & 0.655 \\
\hline PTH [pmol/L] & $3.7 \pm 1.6$ & $3.2 \pm 1.6$ & 0.062 & $3.5 \pm 1.8$ & 0.567 & $3.6 \pm 2.0$ & 0.452 & $4.7 \pm 3.4$ & 0.002 \\
\hline TSH [mU/L] & $2.7 \pm 1.9$ & $1.9 \pm 1.0$ & 0.009 & $2.3 \pm 1.6$ & 0.028 & $1.9 \pm 2.4$ & 0.517 & $2.1 \pm 0.7$ & 0.016 \\
\hline
\end{tabular}

Results are expressed as the mean \pm standard deviation, and significance is expressed as the difference between the selected month and baseline measurement.

Abbreviations: HbA1c - glycated hemoglobin, TG - triacylglycerols, LDL - low density lipoprotein cholesterol, HDL - high density lipoprotein cholesterol, PTH - intact parathyrin, TSH - thyroid stimulating hormone.

Table 4. Micronutrient parameters before and 6, 12, 18, and 24 months after ESG ( $n=20)$.

\begin{tabular}{|c|c|c|c|c|c|c|c|c|c|}
\hline & \multirow{2}{*}{ Baseline } & \multicolumn{8}{|c|}{ Postoperative } \\
\hline & & 6 months & $P$ & 12 months & $P$ & 18 months & $P$ & 24 months & $P$ \\
\hline Vitamin B1 [nmol/L] & $154.36 \pm 18.19$ & $145.49 \pm 17.50$ & 0.028 & $160.47 \pm 26.72$ & 0.001 & $162.88 \pm 23.84$ & 0.087 & $167.80 \pm 24.53$ & 0.023 \\
\hline Vitamin B2 [nmol/L] & $346.91 \pm 41.87$ & $408.75 \pm 50.48$ & 0.001 & $311.52 \pm 41.05$ & 0.001 & $314.04 \pm 51.58$ & 0.015 & $307.8 \pm 47.59$ & 0.008 \\
\hline Vitamin B6 [nmol/L] & $47.71 \pm 29.53$ & $76.59 \pm 94.73$ & 0.177 & $47.62 \pm 29.92$ & 0.272 & $72.21 \pm 55.90$ & 0.028 & $62.62 \pm 39.54$ & 0.154 \\
\hline Vitamin B12 [ng/L] & $340.45 \pm 131.49$ & $295.75 \pm 118.59$ & 0.057 & $293.3 \pm 102.90$ & 0.041 & $325.67 \pm 150.19$ & 0.557 & $317 \pm 103.17$ & 0.538 \\
\hline Ferritin [ug/L] & $105.33 \pm 94.75$ & $107.92 \pm 99.792$ & 0.654 & $96.2 \pm 93.08$ & 0.297 & $112.72 \pm 96.33$ & 0.37 & $107.68 \pm 89.70$ & 0.272 \\
\hline Iron $[\mu \mathrm{mol} / \mathrm{L}]$ & $17.12 \pm 9.45$ & $15.36 \pm 6.99$ & 0.499 & $17.69 \pm 9.88$ & 0.407 & $16.84 \pm 8.46$ & 0.766 & $14.44 \pm 5.02$ & 0.270 \\
\hline Folate $[\mu \mathrm{g} / \mathrm{L}]$ & $7.45 \pm 2.81$ & $7.73 \pm 2.63$ & 0.633 & $8.05 \pm 3.69$ & 0.447 & $8.8 \pm 3.73$ & 0.009 & $8.25 \pm 2.68$ & 0.339 \\
\hline Vitamin $C[\mu \mathrm{mol} / \mathrm{L}]$ & $48.31 \pm 18.58$ & $61.17 \pm 16.35$ & 0.003 & $52.35 \pm 22.71$ & 0.606 & $55.99 \pm 16.72$ & 0.041 & $56.69 \pm 19.81$ & 0.062 \\
\hline Vitamin A $[\mu \mathrm{mol} / \mathrm{L}]$ & $2.34 \pm 0.42$ & $2.27 \pm 0.38$ & 0.484 & $2.11 \pm 0.38$ & 0.001 & $2.17 \pm 0.56$ & 0.04 & $2.07 \pm 0.42$ & 0.003 \\
\hline 25(OH)D [nmol/L] & $38.24 \pm 14.65$ & $60.22 \pm 15.57$ & 0.001 & $43.44 \pm 16.44$ & 0.362 & $51.77 \pm 21.70$ & 0.002 & $35.62 \pm 10.76$ & 0.884 \\
\hline Vitamin D3 [nmol/L] & $53.44 \pm 19.62$ & $84.20 \pm 26.30$ & 0.001 & $64.06 \pm 24.84$ & 0.036 & $67.61 \pm 20.09$ & 0.007 & $46.18 \pm 11.62$ & 0.251 \\
\hline Vitamin E & $31.36 \pm 6.64$ & $31.13 \pm 6.84$ & 0.759 & $29.74 \pm 5.83$ & 0.131 & $30.73 \pm 6.77$ & 0.82 & $32.61 \pm 8.98$ & 0.053 \\
\hline Potassium $[\mathrm{mmol} / \mathrm{L}]$ & $4.35 \pm 0.28$ & $4.38 \pm 0.26$ & 0.720 & $4.25 \pm 0.24$ & 0.599 & $4.19 \pm 0.19$ & 0.044 & $4.371 \pm 0.38$ & 0.885 \\
\hline Calcium [mmol/L] & $2.35 \pm 0.08$ & $2.35 \pm 0.078$ & 0.956 & $2.37 \pm 0.06$ & 0.028 & $2.41 \pm 0.12$ & 0.086 & $2.38 \pm 0.09$ & 0.259 \\
\hline Chloride [mmol/L] & $104.7 \pm 1.55$ & $104.9 \pm 2.69$ & 0.729 & $104.55 \pm 2.01$ & 0.345 & $103.07 \pm 1.94$ & 0.011 & $105.29 \pm 1.43$ & 0.012 \\
\hline Magnesium [mmol/L] & $0.80 \pm 0.079$ & $0.84 \pm 0.06$ & 0.729 & $0.82 \pm 0.06$ & 0.345 & $0.82 \pm 0.07$ & 0.011 & $0.85 \pm 0.06$ & 0.012 \\
\hline Natrium [mmol/L] & $139.25 \pm 1.94$ & $139.8 \pm 2.23$ & 0.231 & $139.45 \pm 1.82$ & 0.108 & $139.13 \pm 1.24$ & 0.735 & $140.79 \pm 1.52$ & 0.016 \\
\hline Phosphorus [mmol/L] & $1.12 \pm 0.18$ & $1.14 \pm 0.14$ & 0.273 & $1.09 \pm 0.17$ & 0.104 & $1.14 \pm 0.23$ & 0.802 & $1.05 \pm 0.18$ & 0.187 \\
\hline
\end{tabular}

Results are expressed as the mean \pm standard deviation, and significance is expressed as the difference between the selected month and baseline measurement. 
taken to evaluate possible preoperative deficiencies of micro- and macronutrients. At least one deficiency was found in $80 \%$ of the patients enrolled in the study. An overview of the incidence of nutritional deficiencies before surgery are shown in Table 1 .

\section{Anthropometry}

We demonstrated a statistically significant reduction in body weight and BMI post-surgery. The most significant weight loss was recorded in the first twelve months after surgery. In the second part of the study, we observed a slight increase in weight, however, patients maintained a reduced weight even after 24 months after surgery. Patients also experienced a statistically significant loss of body fat. Despite the initial weight and fat loss, no significant lean body mass was noted except for the six months post-surgery period. On the contrary, in the following period there was a slight increase in lean body mass compared to the original value before surgery. The results of anthropometric measurements are shown in Table 2.

\section{Postoperative micro and macro nutritional parameters}

The results of the nutritional profile are presented in Table 3. Blood glucose and Insulin levels showed statistically significant decreases in the 6 and 12-month followups. Blood glycated hemoglobin levels were changed, but there were not statistically significant differences. There were not significant changes in plasma lipids. Statistically significant changes after surgery $(P<0.05)$ showed thyreotropin and only after 24 months PTH values $(P=0.002)$. There was a slight increase in prealbumin, but it was not significant.

Plasma concentrations of both vitamin B and fat-soluble vitamins changed statistically significantly. Vitamin B1 levels increased significantly $(P<0.001)$, while plasma B2 levels decreased significantly $(P<0.001)$ over 12 months. Serum vitamin B12 concentration would be significantly reduced $(P<0.05)$. In terms of fat-soluble vitamins, we have seen fluctuations, especially vitamin D3. Here, due to seasonal effects, there was an increase and then a decline. However, at 12 months, at the same time of the year, the level of vitamin D3 after surgery was significantly lower $(P<0.028)$ compared to baseline. Similar fluctuations in levels as in vitamin D3 were reported for $25(\mathrm{OH}) \mathrm{D}$, however the decrease at 12 months compared to baseline was significant. The results of the micronutrient profile are presented in Table 4.

\section{DISCUSSION}

The most effective treatment is bariatric and metabolic surgery, especially in patients with obesity III. degree. On the other hand, in the case of patients with grade I and II obesity, in whom both behavioral and pharmacological treatments have failed, there is a gap in other treatment options. There is now a consensus that bariatric endoscopic methods are an essential part of the treat- ment between pharmacological treatment of low-grade obesity and surgical treatment of patients with high-grade obesity $^{20,21}$. The method of endoscopic sleeve gastroplasty (ESG) is one of the new methods of bariatric endoscopy using gastric plications aimed at the primary treatment of class I and II obesity ${ }^{22}$. This study showed that ESG is an effective procedure for weight loss and improvement in obesity-related diseases. The weight loss in this study was comparable as that obtained with similar endoscopic methods in patients with obesity grades I and II. recently published $^{23,24}$. As with surgical methods, the question is not only the impact of endoscopic bariatric methods on weight reduction, but also the metabolic functions and nutritional status of patients ${ }^{25}$.

\section{Glycemic control}

Long-term follow-up data showed a significant effect of ESG on glycemic homeostasis. Decreases in plasma glucose and other parameters such as HbAlc and insulin have been observed in other similar studies ${ }^{10,14,26}$. The positive effect of the bariatric method on glucose homeostasis can be calculated in connection with weight reduction and decrease in insulin resistance as well as improved tissue response of tissues to insulin ${ }^{2}$. Kaidar-Person et al. ${ }^{27}$ showed that changes in glycemia occur even before significant weight loss. In this context, another mechanism and influence of the role of gastrointestinal hormones such as ghrelin and YY peptide, which affect the regulatory endocrine function of the pancreas and systemic insulin resistance, should be considered. Another important factor is the diet in the postoperative period, which affects glucose homeostasis. In this context, it is important to note that ESG led to less weight loss than surgical methods, on the other hand, changes in glycemic control were significant.

\section{Nutritional deficiencies}

Nutritional deficiencies are systematically and in detail described, especially in surgical methods ${ }^{25,26}$. These deficiencies could potentially reduce the undeniably positive effects of surgery on patients' health. Despite the large number of studies describing nutritional complications in bariatric surgery, complete screening for these deficiencies is not established in routine practice ${ }^{8}$. Previous research in BS shows that the incidence of nutrient deficits in obese individuals is higher compared to normal people $\mathrm{e}^{27,28}$. According to recent data, patients undergoing bariatric surgery are at risk of both micro-and macronutrients, including vitamins B12, B1, C, folate, vitamins A, D and $\mathrm{K}$. At the same time, they are at risk of iron, mucus, zinc, and copper deficiency ${ }^{29}$. On the other hand, very few studies have assessed some nutritional deficiencies in nonsurgery (endoscopic) bariatric procedures ${ }^{15}$. To our knowledge, this study is alone analyzing a broad spectrum of micronutrients after bariatric endoscopic treatment.

One of the most common deficits causing anemia after bariatric intervention are vitamin B12 and folate deficiency ${ }^{30}$. Water-soluble vitamin deficiencies are more common after procedures that induce malabsorption than purely restrictive procedures ${ }^{31}$. To activate vitamin B12, 
the acidic environment of the stomach and pepsin is necessary. Subsequently, this vitamin is bound to the intrinsic factors and absorbed in the terminal ileum. Vitamin B12 uptake after restrictive procedures such as sleeve gastrectomy can become inadequate due to the lower production of hydrochloride acid which is needed to release bounded vitamin B12 in food $^{32}$. The Endomina method used is also a restrictive method, but there is no reduction in the portion of the stomach producing hydrochloride acid and intrinsic factors. Despite all that, we observed a decrease of vitamin B12 in our study. On the other hand, no patients were in clinical deficiency. This change was probably due to a change in diet and intake of foods rich in vitamin B12.

Vitamin B1 deficiency is a concern in bariatric patients, because it can be responsible for neurological complications such as Wernicke's encelopathy and periferial neuropathy ${ }^{33}$. These complications have been observed after a restrictive and malabsorbtion procedures ${ }^{34-36}$. In our study, we did not observe a decrease or deficiency of thiamine, but there was an increase in thiamine concentration. A similar change in plasma has been observed in studies that describe changes in the levels of thiamine after LSG (ref. ${ }^{37,38}$ ) and after gastric bypass ${ }^{39,40}$. Severe thiamine deficiency is a dangerous complication, but prevalence data show that it is relatively $10 w^{25}$.

Vitamin B6 plays a role in amino acid metabolism, gluconeogenesis, and neurotransmitter synthesis. It is important to ensure adequate levels ${ }^{41,42}$. In our study, no patient had a deficiency in serum vitamin B6. Similar data presents a study of patients after LSG and RYGB (ref. ${ }^{30}$ ). Contrary, Damms - Machado reported vitamin B6 deficiencies after LSG, which were not shown by others ${ }^{43}$.

Patients who qualify for obesity surgery present with vitamin D insufficiency with many patients frankly deficient and some with secondary hyperparathyroidism. Vitamin D status may then worsen after obesity surgery, even when supplemental calcium and vitamin D are prescribed $^{44}$. The cause of the vitamin D deficiency state in obesity is not well-understood. It has been proposed that the low vitamin D status might be due to increased vitamin a clearance from serum and enhanced storage of vitamin D by adipose tissue ${ }^{45}$. Patients enrolled in our study were at the border of vitamin $\mathrm{D}$ deficiency before entering the study. During the first six months, $25(\mathrm{OH}) \mathrm{D}$ levels increased. However, there was a subsequent decline. This elevation was probably due to increased sunlight. All patients were interventioned during the winter and early spring. Elevated levels were probably due to exposure to sunlight during the summer. Similar seasonal fluctuations of $25(\mathrm{OH}) \mathrm{D}$ levels in bariatric patients were reported by Luger $^{46}$.

The main limitation concerns the relative small number of patients, secondly, we did not have a comparator group such as patients after sleeve gastrectomy or gastric plication, either surgically or endoscopically.

\section{CONCLUSIONS}

In conclusion, to the best of our knowledge, this is the first study to evaluate the nutritional consequences of ESG. Although weight loss was modest (it was the start of our learning curve), an improved glycemic control was observed as well as a favorable effect on the fat mass/ muscle mass balance after treatment without significant deficit in vitamin levels. These results suggest that such treatment might be considered in the setting of metabolic diseases and therefore deserves further evaluation in a larger cohort of patients. Micronutrient deficiencies in the postoperative period after bariatric surgery are common, particularly in morbid obese individuals compared to the general population. There have been a relatively large number of studies describing micronutrient deficits in surgical publications. Our study is the first to comprehensively describe micronutrient deficits in patients after endoscopic bariatric intervention. In addition, our data show the need for supplementation not only in bariatric surgery patients, but also in patients undergoing bariatric endoscopy.

Acknowledgement: This work was supported by Ministry of Health, Czech Republic - conceptual development of research organization (FNOs/2018).

Author contributions: ZS, DS, MBu: literature search; EM, MB1, JM, AV: clinical assessment; JM, MBu: data analysis; ZS, VH, MB: investigation and data interpretation; ZS, MBu: writing - original draft, review and editing authors contributed eqally.

Conflict of interest statement: The authors state that there are no conflicts of interest regarding the publication of this article.

\section{REFERENCES}

1. Gaur A, Naidu CS, Rao PP, Sharma S, Singh AK, Trehan V, Kulkarni SV, Pathak N, Singh A, Goyal B. The effect of laparoscopic sleeve gastrectomy (LSG) on glycemic control in morbidly obese patients. Int J Surg 2016;28:131-5.

2. Miranda PJ, DeFronzo RA, Califf RM, Guyton JR. Metabolic syndrome: Definition, pathophysiology, and mechanisms. Am Heart J 2005;149(1):33-45.

3. Wolfe BM, Kvach E, Eckel RH. Treatment of Obesity: Weight Loss and Bariatric Surgery. Circ Res 2016;118(11):1844-55.

4. Stanford FC, Kyle TK, Claridy MD, Nadglowski JF, Apovian CM. The influence of an individual's weight perception on the acceptance of bariatric surgery. Obesity 2015;23(2):277-81.

5. Huberty V, Ibrahim M, Hiernaux M, Chau A, Dugardeyn S, Devière J. Safety and feasibility of an endoluminal-suturing device for endoscopic gastric reduction (with video). Gastrointest Endosc American Society for Gastrointestinal Endoscopy; 2017;85(4):833-7.

6. Schulman AR, Thompson CC. Complications of Bariatric Surgery: What You Can Expect to See in Your GI Practice. Am J Gastroenterol 2017;112(11):1640-55.

7. Maggard MA, Shugarman LR, Suttorp M, Maglione M, Sugerman HJ, Livingston EH, Nguyen N, Li Z, Mojica W, Hilton L, Rhodes S, Morton S, Shekelle P. Meta-Analysis: Surgical Treatment of Obesity. Ann Intern Med 2005;142(7):547.

8. Coupaye M, Puchaux K, Bogard C, Msika S, Jouet P, Clerici C, Larger $E$, Ledoux $S$. Nutritional consequences of adjustable gastric banding and gastric bypass: A 1-year prospective study. Obes Surg. 2009;19(1):56-65. 
9. Via MA, Mechanick Jl. Nutritional and Micronutrient Care of Bariatric Surgery Patients: Current Evidence Update. Curr Obes Rep. Current Obesity Reports; 2017;6(3):286-96.

10. Kwon Y, Kim HJ, Lo Menzo E, Park S, Szomstein S, Rosenthal RJ. Anemia, iron and vitamin B12 deficiencies after sleeve gastrectomy compared to Roux-en-Y gastric bypass: a meta-analysis. Surg Obes Relat Dis 2014;10(4):589-97.

11. Lupoli R, Lembo E, Saldalamacchia G, Avola CK, Angrisani L, Capaldo B. Bariatric surgery and long-term nutritional issues. World Diabetes 2017;8(11):464.

12. Roust LR, DiBaise JK. Nutrient deficiencies prior to bariatric surgery. Curr Opin Clin Nutr Metab Care 2017;20(2):138-44.

13. Jastrzebska-Mierzyńska M, Ostrowska L, Hady HR, Dadan J, Konarzewska-Duchnowska E. The impact of bariatric surgery on nutritional status of patients. Wideochirurgia I Inne Tech Maloinwazyjne 2015;10(1):115-24.

14. Ukleja A, Stone RL. Medical and Gastroenterologic Management of the Postbariatric Surgery Patient. J Clin Gastroenterol 2004;38(4):31221.

15. Sullivan S, Stein R, Jonnalagadda S, Mullady D, Edmundowicz S Aspiration therapy leads to weight loss in obese subjects: A pilot study. Gastroenterology 2013;145(6):1245-52.

16. Abu Dayyeh BK, Edmundowicz SA, Jonnalagadda S, Kumar N, Larsen M, Sullivan S, Thompson C, Banerjee S. Endoscopic bariatric therapies. Gastrointest Endosc 2015;81(5):1073-86.

17. Kurian M, Kroh M, Chand B, Mikami D, Reavis K, Khaitan L. SAGES review of endoscopic and minimally invasive bariatric interventions: review of endoscopic and non-surgical bariatric interventions. Surg Endosc 2018;32(10):4063-7.

18. Machytka E, Bužga M, Zonca P, Lautz DB, Ryou M, Simonson DC, Thompson C. Partial jejunal diversion using an incisionless magnetic anastomosis system: 1-year interim results in patients with obesity and diabetes. Gastrointest Endosc 2017;86(5):904-12.

19. Kutáč $P$, Bunc V, Sigmund M. Whole-body dual-energy X-ray absorptiometry demonstrates better reliability than segmental body composition analysis in college-aged students. McLester CN, editor. PLoS One [serial on the Internet]. 2019 [cited 2021 Febr 16] 2019;14:e0215599. Available from: http://dx.plos.org/10.1371/ journal.pone.0215599

20. Cambi MPC, Baretta GAP, Spagnol M, Zilio R, Rossoni C Systematization of Nutritional Care In Endoscopic Treatment for Obesity. Obes Surg 2019;29(3):1074-80.

21. Hedjoudje A, Dayyeh BA, Cheskin LJ, Adam A, Neto MG, Badurdeen D, Morales J, Sartoretto A, Nava G, Vargas E, Sui Z, Fayad L, Farha J, Khashab M, Kalloo A, Alqahtani A, Thompson C, Kumbhari V. Efficacy and Safety of Endoscopic Sleeve Gastroplasty: A Systematic Review and Meta-Analysis. Clin Gastroenterol Hepatol 2019; 18(5):1043-53.

22. Huberty V, Machytka E, Boškoski I, Barea M, Costamagna G, Deviere J. Endoscopic gastric reduction with an endoluminal suturing device: A multicenter prospective trial with 1-year follow-up. Endoscopy 2018;50(12):1156-62.

23. Moura DTH de, Moura EGH de, Thompson CC. Endoscopic sleeve gastroplasty: From whence we came and where we are going. World J Gastrointest Endosc 2019;11(5):322-8.

24. Abu Dayyeh BK, Neto MG, Lopez-Nava G, Sharaiha RZ, Kumbhari $\mathrm{V}$, Wilson EB. Endoscopic sleeve gastroplasty is safe and effective: pitfalls of a flawed systematic review. Surg Obes Relat Dis 2019;15(8):1423-4

25. Lewis CA, de Jersey S, Hopkins G, Hickman I, Osland E. Does Bariatric Surgery Cause Vitamin A, B1, C or E Deficiency? A Systematic Review. Obes Surg 2018;28(11):3640-57.

26. Verger EO, Aron-Wisnewsky J, Dao MC, Kayser BD, Oppert JM, Bouillot JL, Torcivia A, Clément K. Micronutrient and Protein Deficiencies After Gastric Bypass and Sleeve Gastrectomy: a 1-year Follow-up. Obes Surg 2016;26(4):785-96.

27. Kaidar-Person O, Person B, Szomstein S, Rosenthal RJ. Nutritional deficiencies in morbidly obese patients: A new form of malnutrition? Part B: Minerals. Obes Surg 2008;18(7):1028-34.
28. Kaidar-Person O, Person B, Szomstein S, Rosenthal RJ. Nutritional Deficiencies in Morbidly Obese Patients: A New Form of Malnutrition? Part A: Vitamins. Obes Surg 2008;18(8):870-6.

29. Shankar P, Boylan M, Sriram K. Micronutrient deficiencies after bariatric surgery. Nutrition 2010;26(11-12):1031-7.

30. Aarts EO, Janssen IMC, Berends FJ. The gastric sleeve: Losing weight as fast as micronutrients? Obes Surg 2011;21(2):207-11.

31. Antoniewicz A, Kalinowski P, Kotulecka KJ, Kocoń P, Paluszkiewicz R, Remiszewski P, Zieniewicz K. Nutritional Deficiencies in Patients after Roux-en-Y Gastric Bypass and Sleeve Gastrectomy during 12-Month Follow-Up. Obes Surg 2019;29(10):3277-84.

32. Behrns KE, Smith CD, Sarr MG. Prospective evaluation of gastric acid secretion and cobalamin absorption following gastric bypass for clinically severe obesity. Dig Dis Sci 1994;39(2):315-20.

33. Belfiore A, Cataldi M, Minichini L, Aiello ML, Trio R, Rossetti G, Guida B. Short-Term Changes in Body Composition and Response to Micronutrient Supplementation After Laparoscopic Sleeve Gastrectomy. Obes Surg 2015;25(12):2344-51.

34. Punchai S, Hanipah ZN, Meister KM, Schauer PR, Brethauer SA Aminian A. Neurologic Manifestations of Vitamin B Deficiency after Bariatric Surgery. Obes Surg 2017;27(8):2079-82.

35. Frantz DJ. Neurologic complications of bariatric surgery: Involvement of central, peripheral, and enteric nervous systems. Curr Gastroenterol Rep 2012;14(4):367-72.

36. Bongetta D, Zoia C, Luzzi S, Maestro M Del, Peri A, Bichisao G, Sportiello D, Canavero I, Pietrabissa A, Galzio R. Neurosurgical issues of bariatric surgery: A systematic review of the literature and principles of diagnosis and treatment. Clin Neurol Neurosurg 2019;176(January 2019):34-40.

37. Moizé V, Andreu A, Flores L, Torres F, Ibarzabal A, Delgado S, Lacy A Rodriguez $L$, Vidal J. Long-term dietary intake and nutritional deficiencies following sleeve gastrectomy or roux-en-y gastric bypass in a mediterranean population. J Acad Nutr Diet 2013;113(3):400-10.

38. Vinolas $\mathrm{H}$, Barnetche $T$, Ferrandi G, Monsaingeon-Henry M, Pupier E, Collet D, Gronnier C, Gatta-Cherifi B. Oral Hydration, Food Intake, and Nutritional Status Before and After Bariatric Surgery. Obes Surg 2019;29(9):2896-903.

39. Coupaye M, Rivière $P$, Breuil MC, Castel B, Bogard C, Dupré T, Flamant M, Msika S, Ledoux S. Comparison of nutritional status during the first year after sleeve gastrectomy and Roux-en-Y gastric bypass. Obes Surg 2014;24(2):276-83.

40. Ledoux S, Calabrese D, Bogard C, Dupré T, Castel B, Msika S, Larger E, Coupaye M. Long-term Evolution of Nutritional Deficiencies After Gastric Bypass. Ann Surg 2014;259(6):1104-10.

41. Alligier M, Borel A-L, Savey V, Rives-Lange C, Brindisi M-C, Pigue X, Nocca D, Monsaingeon-Henry M, Montastier E, Beliard S, Bossu Estour C, Verkindt $\mathrm{H}$, Coupaye $M$, Lemoine A, Pierre A, Laville $M$, Disse $E$, Bétry C. A series of severe neurologic complications after bariatric surgery in France: the NEUROBAR Study. Surg Obes Relat Dis 2020;16(10):1429-35.

42. Koffman BM, Greenfield LJ, Ali II, Pirzada NA. Neurologic complications after surgery for obesity. Muscle and Nerve 2006;33:166-76.

43. Damms-Machado A, Friedrich A, Kramer KM, Stingel K, Meile T, Küper MA, Königsrainer A, Bischoff S. Pre- and postoperative nutritional deficiencies in obese patients undergoing laparoscopic sleeve gastrectomy. Obes Surg 2012;22(6):881-9.

44. Peterson LA, Cheskin LJ, Furtado M, Papas K, Schweitzer MA, Magnuson TH, Steele K. Malnutrition in Bariatric Surgery Candidates: Multiple Micronutrient Deficiencies Prior to Surgery. Obes Surg 2016;26(4):833-8.

45. Walsh JS, Bowles S, Evans AL. Vitamin D in obesity. Curr Opin Endocrinol Diabetes Obes 2017;24(6):389-94.

46. Luger M, Kruschitz R, Langer F, Prager G, Walker M, Marculescu R, Hoppichler F, Schindler K, Ludvik B. Effects of Omega-Loop Gastric Bypass on Vitamin D and Bone Metabolism in Morbidly Obese Bariatric Patients. Obes Surg 2015;25(6):1056-62. 